\title{
Dynamic Connectivity in a Financial Network Using Time-Varying DCCA Correlation Coefficients
}

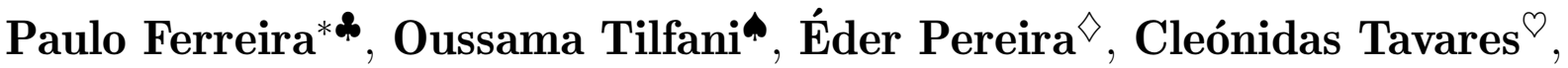 \\ Hernane Pereira $^{\odot}$, and My Youssef El Boukfaoui ${ }^{\oplus}$ \\ *Polytechnic Institute of Portalegre; University of Évora, Portugal \\ "Cadi Ayyad University, Morocco \\ $\diamond$ Federal Institute of Maranhão, Brazil \\ ${ }^{\ominus}$ SENAI CIMATEC School of Technology, Brazil
}

Submitted: January 31, $2021 \bullet$ Accepted: April 19, 2021

\begin{abstract}
This paper aims to analyse the connectivity of 13 stock markets, between 1998 and 2019, with a time-varying proposal, to evaluate evolution of the linkage between these markets over time. To do so, we propose to use a network built based on the correlation coefficients from the Detrended Cross-Correlation Analysis, using a sliding windows approach. Besides allowing for analysis over time, our approach also enables us to verify how the network behaves for different time scales, which enriches the analysis. We use two different properties of networks: global efficiency and average grade, to measure the network's connectivity over time. We find that the markets under analysis became more connected before the subprime crisis, with this behavior extending even after the Eurozone crisis, showing that during extreme events there is an increase in financial risk, as found in the international literature.
\end{abstract}

JEL classification: C58, G01, G15.

Keywords: Centrality, Correlation Coefficient, Detrended Cross-Correlation Analysis, Network.

*Corresponding Author. E-mail: pjsf@uevora.pt 


\section{Introduction}

The increasing interest in financial markets' comovements is explained by both the benefits and risks of increased integration (Obstfeld, 1994; Bekaert et al., 2005, 2014). The evolutionary patterns of correlation between financial markets, especially in specific market stages, could be very informative for market stakeholders, such as investors or policymakers. Furthermore, some specific events affect several different markets, increasing their exposure to possible financial contagion (Beine et al., 2010).

The occurrence of several crisis periods, the availability of an ever increasing amount of data, the constant improvement of computational capacity, and the introduction of new robust econometric approaches, have all allowed for the expansion of research in several fields of finance, including the study of stock market comovements. Most of these studies found that stock market comovements change over time (Brooks and Del Negro, 2004; Kizys and Pierdzioch, 2009), all with increased comovements since early 2000.

The literature contains several studies analysing comovements in financial markets, as well as the use of networks. The next section gives a brief literature review. However, there is a shortage of studies analysing the dynamics of networks and aspects related to time scales, in parallel. Regarding dynamic networks, these allow for the possibility of associating them with the predictability of financial crises, systemic risk, or contagion effect. Additionally, with a multiscale network, the influence of time scales on network connectivity can be identified. For this reason, this article intends to create a network analysis method by joining the use of Detrended Cross-Correlation Analysis (DCCA) correlation coefficients that are based on the sliding windows approach (Tilfani et al., 2019) with the use of networks that are based on the global efficiency method (Latora and Marchiori, 2001) as a connectivity indicator. All in an effort to associate network connectivity with the occurrence of financial crises.

Given that the relationships between different financial markets can alter with the change in the analysed time scales, this work shows the relationship between connectivity and the potential risk in financial markets, combining a network with multiscale networks. Our results show that before the subprime crisis, markets were becoming more connected and remained so between the subprime and the Eurozone crisis and also after the Eurozone crisis. Just after that crisis, connectivity seemed to decrease. Our results reinforce the international literature that shows a relationship between both connectivity and financial risk (Tabak et al., 2014; Minoiu et al., 2015; Acemoglu et al., 2015; Diebold and Yılmaz, 2014; Wang et al., 2017).

The remainder of the paper is organized as follows. Section 2 reviews the literature on the issues of stock market comovements and networks. Section 3 presents the methodology and data used in the paper. Section 4 presents the results. Finally, section 5 concludes the paper. 


\section{A Literature Review on Stock Market Comovements}

The study of how stock markets comove is not a new concept. A great number of studies are found within the field. For this reason, and because of the sheer difficulty of making an exhaustive literature review, we focus our literature review on papers considering three different topics. First, the approaches used to analyse comovements between markets. Second, the use of Econophysics applications to analyse those comovements. Third, the use of networks to explain market linkages. Therefore, we divide this literature review into three subsections. These will follow our objective of building multiscale networks in order to analyse financial markets and the possibility of increased financial risk, according to the evolution of those networks.

\subsection{First Approaches to Analyse Stock Market Comovements}

The first type of approach to analysing stock market comovements used correlation coefficients. This is the most common way to assess the existence of comovements between financial assets and the way crisis affects those comovements. For example, considering the October 1987 crash, King and Wadhwani (1990), as well as Bertero and Mayer (1990), analysed covariances and correlations caused by that crash. Studies, such as Brooks and Del Negro (2004), applied sliding windows approaches in order to evaluate the behaviour of correlation coefficients over time. They studied comovements with rolling windows correlation coefficients, allowing for the continuous analysis of comovements. ARCH and GARCH models can also be used to analyse market linkages (Longin and Solnik, 1995; Edwards and Susmel, 2000), as well as cointegration methodologies (Kasa, 1992; Serletis and King, 1997). Studies of the different linkage behaviour between financial markets over time could also use methodologies that apply switching regimes (Hassler, 1995; Edwards and Susmel, 2000).

Prior studies on this topic, including most of the previously identified work, are based on the application of linear measures. However, financial markets are usually affected by both non-linearities and phenomena known in the financial literature as stylized facts. These include fat tails, self-similarity, non-stationarity, or non-heterogeneity (Wang et al. 2012; Valls, 2012; Usman et al., 2015; Martin-Montoya et al., 2015).

It is in this context that Peters (1991, 1994) proposes the Fractal Market Hypothesis (FMH). FMH is based on several of these features that are observed in financial markets (Li et al., 2015). It is in opposition to the more mainstream Efficient Market Hypothesis (EMH) of Fama (1965, 1970). In fact, EMH considers the homogeneity of investors, which is an assumption that is not well explained in times of turbulence. On the contrary, and according to the FMH, the existence of heterogeneity among investors implies that markets could see their market liquidity assured. Authors, such as Rachev et al. (1999) and Kristoufek et al. (2012), conclude that the existence of a given investment horizon could end in the occurrence of extreme events, making markets unstable. 
Generally, the application of linear measures, the first to be used in this context, tended to identify the increased linkage in financial markets. However, considering the limitations of these approaches, as well as the possible existence of non-linear patterns, which should be explained, a new strand of work emerged. It uses statistical physics approaches to analyse financial markets' behaviour in general, including stock market comovements.

\subsection{Econophysics and its Applications to Financial Market Comove- ments}

The possible limitations in traditional models or hypotheses, like the EMH, allied to the increase in data, drew physicists' attention to financial markets, allowing for the creation of a multidisciplinary research field called Econophysics. The main objective of this field is to analyse the financial markets as complex systems (Stanley et al. 1996; Mantegna and Stanley, 1999), this is despite the proximity between physics and finances that were started earlier (Mandelbrot, 1963).

One of the assumptions that could be analysed, as previously mentioned, is the homogeneous investor interests. In fact, investors' different interests could imply that they behave differently according to both short- and long-term horizons. This behaviour could not be observed by all the methodologies used in the existing literature. To attain this objective, Rua and Nunes (2009) used a wavelet analysis to analyse the comovements of stock markets in developed economies. They concluded that market agents' interest is different in the short and long run, meaning that the international diversification is more possible in the short run.

Similarly, the application of methodologies, which allow for the study of multiscale, could help to distinguish between the short and long runs. This is the reason for using methodologies like the Detrended Cross-Correlation Analysis (DCCA), which is also used in this paper. With the DCCA, Ma et al. (2013) analyse the relationship between some Asian stock markets, El Alaoui and Benbachir (2013) make an analysis of Middle East and North African indices, Shi et al. (2014) assess the cross-correlations between U.S. and Chinese stock indices and Ferreira (2017) analyses the particular case of increased stock market integration between Portugal and Brazil. Aiming to study the evolution of comovements over time, Tilfani et al. (2019) proposed for the application of sliding windows to the DCCA correlation coefficient, assessing the continuous evolution of stock markets' comovements, investigating the dynamic multiscale interdependence between major stock markets.

The use of methodologies like the DCCA, originating in statistical physics, allows for the understanding of financial markets as complex systems. The complexity of financial markets, related to the existence of many agents with different interests, is potentiated during turmoil periods. This is when systems reveal different characteristics more clearly than in calm periods (Sornette, 2003). In fact, the analysis of the impact of crises on 
comovement behaviour is not new. For example, Forbes and Rigobon (2002) studied the evolution of correlation between stock markets in order to distinguish between contagion and interdependence. With the former being related to the shift in market linkages caused by a given phenomenon, and the latter as the change in comovements caused by the existence of a change in volatility.

In particular, the use of Econophysics approaches increases the possibilities of analysing financial markets, extending the different analyses to non-linear approaches, instead of only linear ones, as well as considering different multiscale analyses. In fact, this last feature allows for an extension of the analyses, for example, in the context of network application.

\subsection{The Use of Networks to Explain Market Linkages}

Since the 90s, the use of new network topologies, such as small world (Watts and Strogatz, 1998) and scale-free (Barabási and Albert, 1999), increased the use of networks in financial markets. The use of networks is also related to the interest in studying complex systems. Complexity, marked by the coexistence of many agents and their different interests in different time scales, cannot be predicted from an isolated understanding of each of these parts (Costa et al., 2007). Network theory has allowed economists to study how different agents interact with and to identify the most influential agent, being applied to different areas (Jackson, 2010; Schweitzer et al., 2009; Ferreira, 2017).

According to Mantegna (1999), complex networks can capture a large amount of information about financial series. This is also useful for studying the phenomenon of market integration. Moreover, those complex networks can identify characteristics such as centrality, medium degree, and network hub, as well as others. Analysing how companies of the New York Stock Exchange (NYSE) were connected, Mantegna (1999) applied the Minimum Spanning Tree (MST) method. With high-frequency data, Bonanno et al. (2001) also analysed the major stocks traded in the U.S., showing that the correlations between them were different for different time horizons. Onnela et al. (2003) also studied NYSE in order to build hierarchical networks, which is one of the main uses of the MST (Junior and Franca, 2012; Matesanz et al., 2014; Huang et al., 2015). Furthermore, with NYSE, Kenett et al. (2010) applied a Partial Correlation Network (PCN) with a dynamic analysis, concluding on the existence of persistence within the financial sector. Kristoufek et al. (2012) applied MST to the correlation between biofuels and other commodities (for example, before and after a period of food crisis), concluding that correlations increased with the crisis. A similar analysis was made to assess the relationship between food and fuel commodities by Kristoufek et al. (2013).

Recently, complex networks have been used to analyse evidence of contagion (Gai and Kapadia, 2010; Glasserman and Young, 2015; Acemoglu et al., 2015). These studies relate the contagion effect to the transition phase from a given moment, using network connectivity as a proxy for the spread of financial shocks. In this context, Diebold and Yilmaz 
(2014) used complex networks, demonstrating that markets increased their connection during the 2008 crisis. Complex networks were also used to measure specific issues of risk, such as systemic risk in the bank payment system, or as a tool to analyse the possibility of financial crises occurring (Soramäki et al., 2007; Minoiu and Reyes, 2013; Battiston et al., 2012; Yan et al., 2014; Tabak et al., 2014; Minoiu et al., 2015).

Methodologies that are based on multiscale networks could give us different types of analysis. Wang et al. (2013ab) combined the DCCA correlation coefficient and the MST. This resulted in a multiscale network for 44 different currencies between 2007 and 2012, finding a predominance of both the dollar and the euro. Kwapień et al. (2017) generalized the MST, introducing a family of minimum spanning trees that are dependent on the periodicity of the data, allowing for the analysis of data ranging from one minute to one month. Pereira et al. (2019) also applied a network approach, based on the DCCA correlation coefficient, to analyse 20 financial markets before and after the 2008 crisis, and concluded on the increased connectivity after the crisis.

\section{Methodology and Data}

We propose the construction of a network that is based on the DCCA correlation coefficient that also has a sliding windows approach. Proposed by Podobnik and Stanley (2008), the DCCA is used to estimate long-range cross-correlations between two different time series $x_{k}$ and $y_{k}$, with the same length $(k=1, \ldots, t)$, which are integrated in the first step. First, $X(t)=\sum_{i=1}^{t}\left(x_{i}-\langle x\rangle\right)$ and $Y(t)=\sum_{i=1}^{t}\left(y_{i}-\langle y\rangle\right)$ are calculated, with $\langle x\rangle$ and $\langle y\rangle$ as the mean observed values of the original time series. The new profiles $X(t)$ and $Y(t)$ are then divided into boxes of length $n$, and for those boxes local trends $\tilde{x}(t)$ and $\tilde{y}(t)$ are calculated using ordinary least squares. With the trends, profiles $X(t)$ and $Y(t)$ are detrended, resulting in $X_{n}(t)=X(t)-\tilde{x}(t)$ and $Y_{n}(t)=Y(t)-\tilde{y}(t)$. These are then used to calculate the detrended covariances given by:

$$
f_{D C C A}^{2}=\frac{1}{n-1} \sum_{t=i}^{i+n}(X(t) Y(t))
$$

calculated for each box. Summing all boxes of size $n$, we have:

$$
F_{D C C A}^{2}(n)=\frac{1}{N-n} \sum_{i=1}^{N-n} f_{D C C A}^{2}
$$

After repeating the same process for all the existing length boxes, as well as the regression of the $\log$-log relationship between $F_{D C C A}^{2}(n)$ and $n$, we have a power law given by $F_{D C C A}(n) \sim n^{\lambda}$, with $\lambda$ the DCCA parameter, which measures the long-range dependence between the original time series.

Considering that the DCCA is a covariance measure, Zebende (2011) proposes using 
the correlation coefficient given by:

$$
\rho D C C A(s, T)=\frac{F^{2}{ }_{D C C A}(s)}{F_{D F A\left\{x_{i}\right\}}(s) F_{D F A\left\{y_{i}\right\}}(s)}
$$

with $F_{D F A}$ being the fluctuation function of the Detrented Fluctuation Analysis (DFA) (Peng et al., 1994) used to analyse the serial dependence of individual time series.

The proposed correlation coefficient $\rho \mathrm{DCCA}$ has the desired properties of a correlation coefficient, in particular $-1 \leq \rho \operatorname{DCCA}(n) \leq 1$. It is null when variables are not correlated, being positive (negative) depending on the existence of persistent (anti-persistent) correlations. This is a scale dependent coefficient, which means it can be calculated for both short- and long-time scales and can also be used to distinguish between the behaviour in the short and long run. Moreover, it is efficient in the presence of non-stationary time series (Kristoufek, 2014b a; Piao and Fu, 2016; Zhao et al., 2017). This correlation coefficient could also be tested according to the procedures of Podobnik et al. (2011).

As calculations of the DCCA correlation coefficient could have volatility bias, in order to reduce that bias, filtered series were used. In particular, we considered $r_{t, f}=r_{t} / \sqrt{h_{t}}$, with $h_{t}$ as the conditional variance of a $\operatorname{GARCH}(1,1)$ process, transformation suggested by Cajueiro and Tabak (2004), as well as Kristoufek (2012).

As we aim to build a dynamic network, to measure the linkage between stock markets in a continuous way, we use sliding windows that calculate time varying DCCA correlation coefficients. This approach was presented, for example, in Tilfani et al. (2019), who used it to analyse the continuous comovements between stock markets. We used windows of 1,000 observations to, not only guarantee the robustness of the estimated correlation coefficients, but also to ensure the trade-off between the long-term and local features.

These correlation coefficients are used to build a dynamic complex network, which like any complex network, can be represented as a graph of a set $\mathrm{R}$, with no weights in their connections, and is defined by vertices $v=\left\{v_{1}, v_{2}, v_{3}, \ldots, v_{N}\right\}$ and by the edges $\epsilon=\left\{e_{1}, e_{2}, e_{3} \ldots, e_{M}\right\}$, which connect the different pairs of nodes. The number of edges is given by the cardinality of the set of vertices $n=|V|$ and the number of arcs is given by the cardinality of the set of arcs (Newman, 2018). A weighted and directed network can be represented by an $n \times n$ cost matrix given by $W=\left\{w_{i j}\right\}$. If $w_{i j}=0$, there is no directed connection between $i$ and $j$, but a directed connection between $j$ and $i$ may exist if $w_{j i} \neq 0$. In order to analyse network connectivity, we use the global efficiency property. This is defined by Latora and Marchiori (2001) as:

$$
E(G)=\frac{1}{n(n-1)} \sum_{i \neq j \in G} \frac{1}{d(i, j)}
$$

with $d(i, j)$ being the average minimal path length between $i$ and $j$. The average degree 
of an undirected network is given by:

$$
\langle k\rangle=\frac{1}{n} \sum_{i=1}^{n} k_{i}
$$

Global efficiency was already used as an indicator of network connectivity by Yan et al. (2014). In this study, we extend this by using multiscale methods, associating this indicator by calculating the network based on the DCCA correlation coefficients and by using a sliding windows approach.

This paper takes 13 stock market indices: EuroStoxx 600 (Eurozone), NYSE Composite (US), FTSE 100 (UK), CAC40 (France), DAX30 (Germany), NIKKEI225 (Japan), S\&P/TSX (Canada), MIB (Italy), Bovespa (Brazil), MOEX (Russia), NIFTY500 (India), SSE (China), and JSE (South Africa). These indices reflect the most industrialized economies (G7), as well as the BRICS, as indicators of emerging markets. It also reflects EuroStoxx, since the Eurozone is a very relevant economic area (despite including French, Italian, and German companies, it also includes firms from a very large economic area that is comprised of 19 countries). Our sample starts on January 1, 1998 and ends on October 29, 2019 with a total of 5,694 observations. As usual, we also transformed closing prices in logarithmic returns.

\section{Results and Discussion}

Figure 1 presents the results of the overall efficiency of the network for a time scale of 4. The blue lines identify both the subprime and Eurozone crises, corresponding to the peaks of the VIX index - an indicator of volatility. The figure reveals an increase in the efficiency of the network from the beginning of 2005, up until April 2012. After that, the efficiency of the network gradually decreased, stabilizing its value around 0.3 at the beginning of 2018. Considering the blue lines, even before the beginning of the subprime crisis, connectivity was already observed to be increasing. This increase continued until just after the beginning of the Eurozone debt crisis when it started to decrease.

For the scales of 32, 64, and 125 days, with the global efficiency represented in Figure 2 , the degree of efficiency is higher when compared to the scale of 4 days. It means that, in the long run, markets are more connected than in the short run. Efficiency levels are close for these scales. However, at the beginning of the sample, the highest scale has higher values, while the end of the sample has lower ones. This result means that at the beginning of the sample, the long run was more relevant than the short run with a change in the pattern after the crisis. This result is consistent with both the FMH and the difference in behaviour across different time scales. Despite this, there is similar behaviour to that found in the 4-day scale, since connectivity starts to rise from the beginning of 2005 and reaches a peak between the two crises. After a period of stabilized connectivity, it started 
Figure 1: Global efficiency for the time scale equal to 4

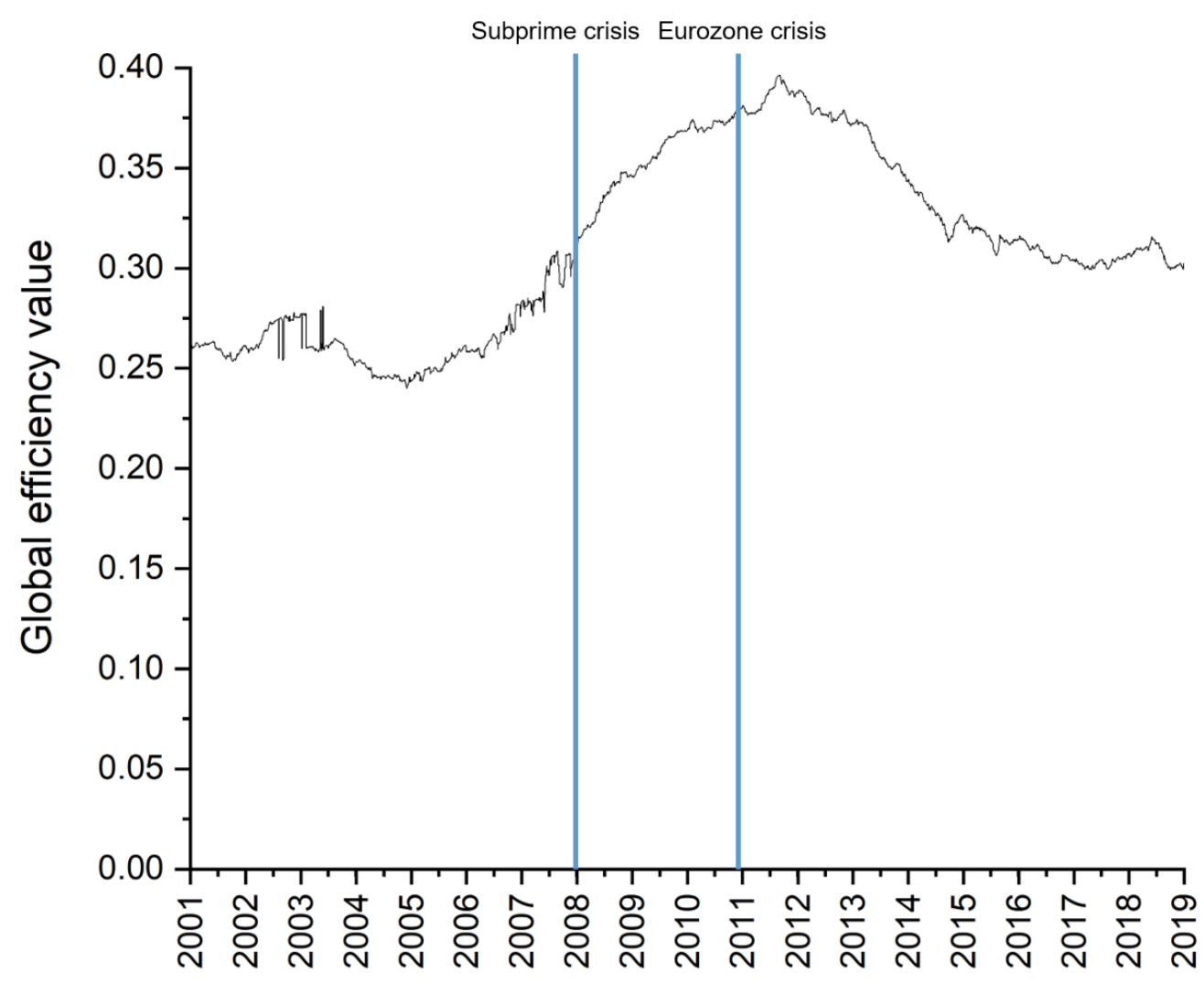

Note: The values illustrated on the graph are given for 01/11 in subsequent years. Source: Authors' calculation.

to fall in late 2013 until reaching a minimum value in late 2017 with a new stabilization, with similar values to those found before the beginning of the global financial crisis.

Considering the value of the networks' global efficiency, in order to confirm the difference across the different periods and across the different time scales, we performed different ANOVA tests in order to compare means. Considering the different time periods, we took three different sub-periods as follows: P1 - from the beginning of the sample until the end of August 2007 (the period before both crises); P2 - from September 2007 until the end of 2014 (the period of both crises); P3 - from 2015 to the end of the sample (the period after both crises).

The analysis of the mean comparison for the global efficiency is presented in Table 1. There, we can conclude that the means are statistically different across the different time periods, while the Scheffé test always identifies three different subsets. It is interesting to note that the mean of P2 is always the highest, meaning that connectivity during the crises is higher. Nevertheless, for lower time scales, the value of P3 is higher than in the P1 period, with contrary results in the higher time scales. This means that investors' preferences could change with the crises. Despite this, the mean value of global efficiency 
Figure 2: Global efficiency for multiple scales

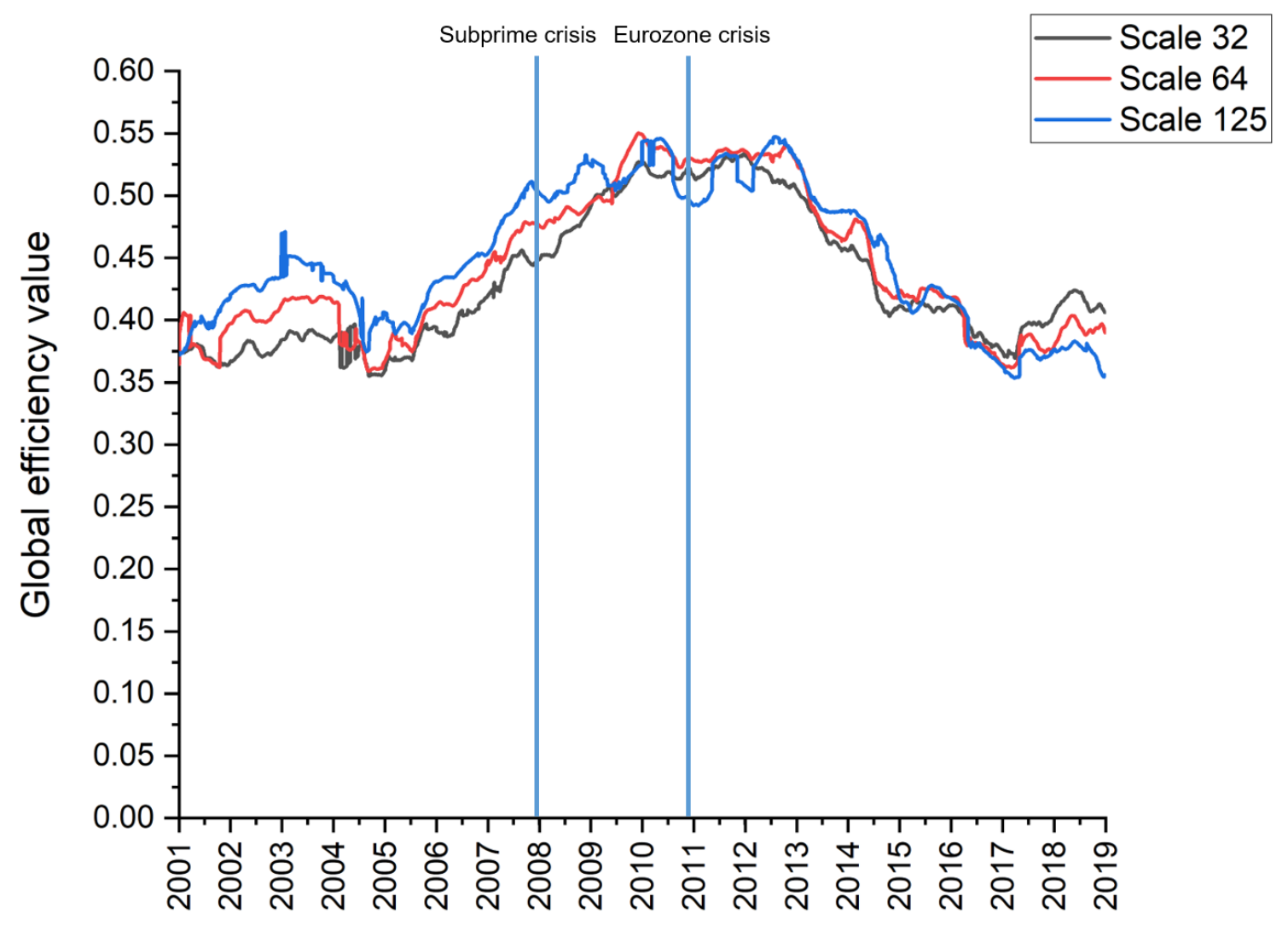

Note: The values illustrated on the graph are given for 01/11 in subsequent years. Source: Authors' calculation.

generally increases with time scales, as identified in Table2. This confirms that the means across the different time scales are statistically different, forming four different subsets.

Table 1: Mean comparison for global efficiency across different periods

\begin{tabular}{lcccc}
\hline & $\mathbf{n}=\mathbf{4}$ & $\mathbf{n}=\mathbf{3 2}$ & $\mathbf{n}=\mathbf{6 4}$ & $\mathbf{n}=\mathbf{1 2 5}$ \\
\hline Pre-crises period (P1) & 0.236 & 0.388 & 0.406 & 0.429 \\
Crises periods (P2) & 0.362 & 0.499 & 0.513 & 0.515 \\
Post-crises period (P3) & 0.311 & 0.406 & 0.402 & 0.399 \\
Anova p-value & 0.000 & 0.000 & 0.000 & 0.000 \\
Homogeneous subsets & $\mathrm{P} 1 \neq \mathrm{P} 2 \neq \mathrm{P} 3$ & $\mathrm{P} 1 \neq \mathrm{P} 2 \neq \mathrm{P} 3$ & $\mathrm{P} 1 \neq \mathrm{P} 2 \neq \mathrm{P} 3$ & $\mathrm{P} 1 \neq \mathrm{P} 2 \neq \mathrm{P} 3$ \\
\hline
\end{tabular}

Source: Authors' calculation.

Figure 3 analyses the average degree of the network, revealing that for the four scales analysed, the average degree increased even before the subprime crisis. After this event, the average degree for the smaller scales remained high, while the degree for the larger scales decreased, mainly for the 125-day scale. The average degree for all scales remained high at the beginning of the Eurozone crisis, until they started to decrease at the beginning of 2015 , for higher time scales. 
Table 2: Mean comparison for global efficiency across different time scales

\begin{tabular}{lc}
\hline & Global efficiency \\
\hline $\mathrm{n}=4(\mathrm{~S} 4)$ & 0.311 \\
$\mathrm{n}=32(\mathrm{~S} 32)$ & 0.432 \\
$\mathrm{n}=64(\mathrm{~S} 64)$ & 0.443 \\
$\mathrm{n}=125(\mathrm{~S} 125)$ & 0.451 \\
Anova p-value & 0.000 \\
Homogeneous subsets & $\mathrm{S} 4 \neq \mathrm{S} 32 \neq \mathrm{S} 64 \neq \mathrm{S} 125$ \\
\hline
\end{tabular}

Source: Authors' calculation.

Figure 3: Average degree for multiple scale

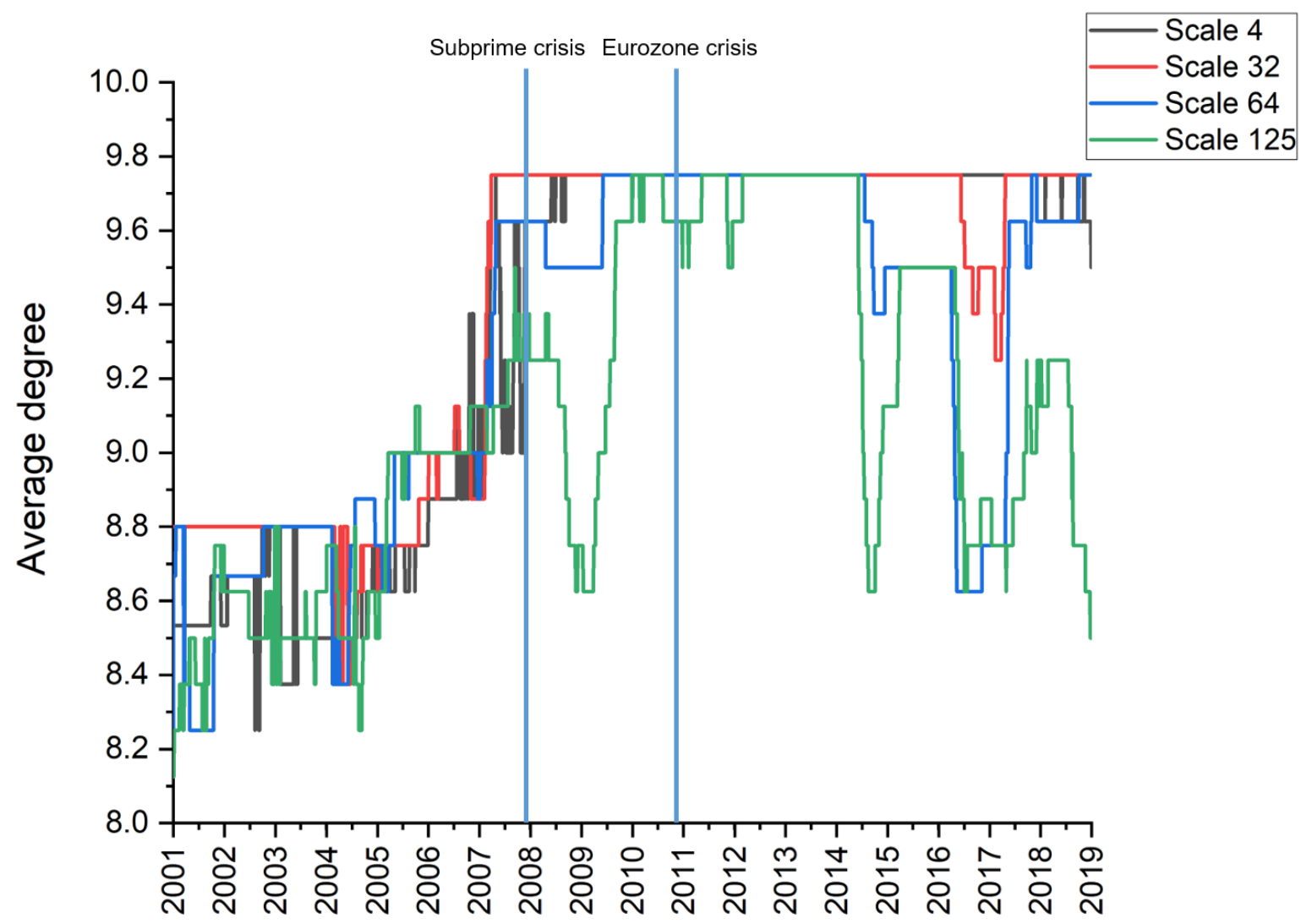

Note: The values illustrated on the graph are given for $01 / 11$ in subsequent years.

Source: Authors' calculation.

The results corroborate with those of Diebold and Ylmaz (2014), which relate the connectivity found in the network with the possibility of financial crises. Moreover, they are consistent with the results of Tilfani et al. (2019), who found evidence in favour of the FMH. The results show that before the subprime crisis, markets became more connected. This implies a greater financial risk, as is identified, for example, by Diebold and Yılmaz (2014); Acemoglu et al. (2015), or Wang et al. (2017). This increase in risk implies that a given shock could be passed on to the entire network, increasing the chances of a contagion effect. It should be noted that before the subprime crisis, network connectivity had been 
increasing and increased even after the Eurozone crisis, showing that the markets remained strongly connected during this period, increasing the likelihood of risk.

A similar exercise to compare means was performed with this average degree indicator, with the analysis across different periods presented in Table 3 , as well as across different time scales in Table 4. Once again, the ANOVA framework identifies that the means are not all equal. In the 4-day time scale, it is possible to conclude that the average degree increased from P1 to the remainder, albeit without a statistical difference between the mean of P2 and P3. For the remaining cases, all the periods are inserted in different subgroups but with P2 having the highest mean value. The results presented in Table 4 reveal that the average degree varies across the different time scales, although with higher values in the lower time scales and lower values in the higher time scales.

Table 3: Mean comparison for the average degree across different periods

\begin{tabular}{lcccc}
\hline & $\mathbf{n}=\mathbf{4}$ & $\mathbf{n}=\mathbf{3 2}$ & $\mathbf{n}=\mathbf{6 4}$ & $\mathbf{n}=\mathbf{1 2 5}$ \\
\hline Pre-crises period (P1) & 8.732 & 8.895 & 8.839 & 8.732 \\
Crises periods (P2) & 9.732 & 9.750 & 9.697 & 9.515 \\
Post-crises period (P3) & 9.743 & 9.697 & 9.391 & 9.112 \\
Anova p-value & 0.000 & 0.000 & 0.000 & 0.000 \\
Homogeneous subsets & $\mathrm{P} 1 \neq \mathrm{P} 2=\mathrm{P} 3$ & $\mathrm{P} 1 \neq \mathrm{P} 2 \neq \mathrm{P} 3$ & $\mathrm{P} 1 \neq \mathrm{P} 2 \neq \mathrm{P} 3$ & $\mathrm{P} 1 \neq \mathrm{P} 2 \neq \mathrm{P} 3$ \\
\hline
\end{tabular}

Source: Authors' calculation.

Table 4: Mean comparison for the average degree across different time scales

\begin{tabular}{lc}
\hline & Average degree \\
\hline $\mathrm{n}=4(\mathrm{~S} 4)$ & 9.355 \\
$\mathrm{n}=32(\mathrm{~S} 32)$ & 9.411 \\
$\mathrm{n}=64(\mathrm{~S} 64)$ & 9.289 \\
$\mathrm{n}=125(\mathrm{~S} 125)$ & 9.110 \\
Anova p-value & 0.000 \\
Homogeneous subsets & $\mathrm{S} 4 \neq \mathrm{S} 32 \neq \mathrm{S} 64 \neq \mathrm{S} 125$ \\
\hline
\end{tabular}

Source: Authors' calculation.

Combining these results show that the crises influenced increased network connection, with the second period having a clearly higher level of connection. After the crises had passed, there is mixed evidence where, in some cases, the connectedness of the network was lower than in the first period and higher in others. Even though these could be considered contradictory results, they confirm the difference of behaviour in the different time scales, consistent with the FMH.

\section{Conclusion}

Networks have been consolidated as instruments of financial market analysis due to the possibility of analysing their topology (for networks or communities), as well as the cen- 
trality of the individuals forming them. Recently, the association between network connectivity and the possibility of financial crises has been shown. It is known that extreme events, such as crises, are very damaging to the economy. They increase national debt, decrease income, and generate unemployment.

In this work, we use a wide sample, including both the subprime and Eurozone crises, in order to analyse the pattern of connectivity. The results show that during these events, network connectivity started to increase before the subprime crisis and intensified during the Eurozone crisis. This situation demonstrates the increased financial risk of the markets considered, according to Diebold and Yllmaz (2014); Tabak et al. (2014); Minoiu et al. (2015); Acemoglu et al. (2015); Wang et al. (2017). This paper also contributes by confirming that network connectivity increased in various time scales, and by using the concept of global efficiency to calculate the financial relationships during the analysed period of time.

Recalling the paper by Forbes and Rigobon (2002), it is important to determine whether the increase of the correlations caused by a given crisis episode could be considered as a contagion or just an increase of interdependence. This depends on it just being due to increased volatility or caused by any shock transmission mechanism. Considering that the network is built on the framework of filtered returns, and that there is some evidence of increased connectedness of the network after the crises (compared to the pre-crises period), we believe we are in the presence of a contagion effect. Moreover, it is important to highlight the different behaviour in the different time scales. This is consistent with the fractal market hypothesis and the possibility of investors having different horizon preferences.

Associating network connectivity with the occurrence of financial crises makes it possible to create indicators to assist in predicting these events, so as to avoid or to mitigate them. Therefore, this information can be used in hedge funds, large banks, or governments to help prevent events such as crises. In the future, it will also be possible to analyse the effects of the current crisis that was caused by COVID-19, which having a different origin, could have a different impact on network connectivity behaviour.

\section{References}

Acemoglu, D., Ozdaglar, A., and Tahbaz-Salehi, A. (2015). Systemic Risk and Stability in Financial Networks. American Economic Review, 105(2):564-608.

Barabási, A. L. and Albert, R. (1999). Emergence of Scaling in Random Networks. Science, 286(5439):509-512.

Battiston, S., Puliga, M., Kaushik, R., Tasca, P., and Caldarelli, G. (2012). DebtRank: Too Central to Fail? Financial Networks, the FED and Systemic Risk. Scientific Reports, 2:541. 
Beine, M., Cosma, A., and Vermeulen, R. (2010). The Dark Side of Global Integration: Increasing Tail Dependence. Journal of Banking \& Finance, 34(1):184-192.

Bekaert, G., Ehrmann, M., and Fratzscher, M. (2014). The Global Crisis and Equity Market Contagion. The Journal of Finance, 69(6):2597-2649.

Bekaert, G., Harvey, C., and Lundblad, C. (2005). Does Financial Liberalization Spur Growth? Journal of Financial Economics, 77:3-56.

Bertero, E. and Mayer, C. (1990). Structure and Performance: Global Interdependence of Stock Markets Around the Crash of October 1987. European Economic Review, 34:1155-1180.

Bonanno, G., Lillo, F., and Mantegna, R. N. (2001). High-Frequency Cross-Correlation in a Set of Stocks. Quantitative Finance, 1(1):96-104.

Brooks, R. and Del Negro, M. (2004). The Rise in Comovement Across National Stock Markets: Market Integration or IT Bubble? Journal of Empirical Finance, 11:659-680.

Cajueiro, D. and Tabak, B. (2004). The Hurst Exponent over Time: Testing the Assertion that Emerging Markets are Becoming More Efficient. Physica A, 336(3-4):521-537.

Costa, L. D. F., Rodrigues, F. A., Travieso, G., and Villas Boas, P. R. (2007). Characterization of Complex Networks: A Survey of Measurements. Advances in Physics, $56(1): 167-242$.

Delignières, D., Ramdani, S., Lemoine, L., Torre, K., Fortes, M., and Ninot, G. (2006). Fractal Analyses for 'Short' Time Series: A Re-assessment of Classical Methods. Journal of Mathematical Psychology, 50:525-544.

Diebold, F. X. and Yllmaz, K. (2014). On the Network Topology of Variance Decompositions: Measuring the Connectedness of Financial Firms. Journal of Econometrics, 182(1):119-134.

Edwards, S. and Susmel, R. (2000). Interest Rate Volatility and Contagion in Emerging Markets: Evidence From the 1990s. NBER Working Paper 7183.

El Alaoui, M. and Benbachir, D. (2013). Multifractal Detrended Cross-Correlation Analysis in the MENA Area. Physica A, 392(23):5985-5993.

Fama, E. (1965). The Behavior of Stock-Market Prices. The Journal of Business, 38(1):34105.

Fama, E. (1970). Efficient Capital Markets: A Review of Theory and Empirical Work. The Journal of Finance, 25:383-417. 
Ferreira, P. (2017). Portuguese and Brazilian Stock Market Integration: A Non-linear and Detrended Approach. Portuguese Economic Journal, 16(1):49-63.

Forbes, K. and Rigobon, R. (2002). No Contagion, Only Interdependence: Measuring Stock Market Co-movements. The Journal of Finance, 57(5):2223-2261.

Gai, P. and Kapadia, S. (2010). Contagion in Financial Networks. Proceedings of the Royal Society A: Mathematical, Physical and Engineering Sciences, 466(2120):2401-2423.

Glasserman, P. and Young, H. P. (2015). How Likely Is Contagion in Financial Networks? Journal of Banking \& Finance, 50:383-399.

Hassler, J. (1995). Regime Shifts and Volatility Spillovers on International Stock Markets. Seminar Paper 603, Institute for International Economic Studies.

Huang, S., Chow, S. C., Xu, R., and Wong, W. K. (2015). Analyzing the Hong Kong Stock Market Structure: A Complex Network Approach. Available at SSRN: https: //ssrn.com/abstract=2633433.

Jackson, M. O. (2010). Social and Economic Networks. Princeton University Press.

Junior, L. S. and Franca, I. D. P. (2012). Correlation of Financial Markets in Times of Crisis. Physica A, 391(1-2):187-208.

Kasa, K. (1992). Common Stochastic Trends in International Stock Markets. Journal of Monetary Economics, 29:95-124.

Kenett, D. Y., Tumminello, M., Madi, A., Gur-Gershgoren, G., Mantegna, R. N., and Ben-Jacob, E. (2010). Dominating Clasp of the Financial Sector Revealed by Partial Correlation Analysis of the Stock Market. PloS One, 5(12):e15032.

King, M. and Wadhwani, S. (1990). Transmission of Volatility Between Stock Markets. Review of Financial Studies, 3(1):5-33.

Kirchner, M., Schubert, P., Schmidtbleicher, D., and Haas, C. (2012). Evaluation of the Temporal Structure of Postural Sway Fluctuations Based on a Comprehensive Set of Analysis Tools. Physica A, 391:4692-4703.

Kizys, R. and Pierdzioch, C. (2009). Changes in the International Comovement of Stock Returns and Asymmetric Macroeconomic Shocks. Journal of International Financial Markets, Institutions and Money, 19(2):289-305.

Kristoufek, L. (2012). Fractal Market Hypothesis and the Global Financial Crisis: Scaling, Investment Horizons and Liquidity. Advances in Complex Systems, 15(6):1250065.

Kristoufek, L. (2014a). Detrending Moving-Average Cross-Correlation Coefficient: Measuring Cross-Correlations Between Non-stationary Series. Physica A, 406:169-175. 
Kristoufek, L. (2014b). Measuring Correlations Between Non-stationary Series with DCCA Coefficient. Physica A, 402:291-298.

Kristoufek, L., Janda, K., and Zilberman, D. (2012). Correlations Between Biofuels and Related Commodities Before and During the Food Crisis: A Taxonomy Perspective. Energy Economics, 34(5):1380-1391.

Kristoufek, L., Janda, K., and Zilberman, D. (2013). Regime-Dependent Topological Properties of Biofuels Networks. The European Physical Journal B, 86(2):40.

Kwapień, J., Oświęcimka, P., Forczek, M., and Drożdż, S. (2017). Minimum Spanning Tree Filtering of Correlations for Varying Time Scales and Size of Fluctuations. Physical Review E, 95(5):052313.

Latora, V. and Marchiori, M. (2001). Efficient Behavior of Small-World Networks. Physical Review Letters, 87(19):198701.

Li, D., Kou, Z., and Sun, Q. (2015). The Scale-Dependent Market Trend: Empirical Evidences Using the Lagged DFA Method. Physica A, 433:26-35.

Longin, F. and Solnik, B. (1995). Is the Correlation in International Equity Returns Constant: 1960-1990? Journal of International Money and Finance, 14(1):3-26.

Ma, F., Wei, Y., and Huang, D. (2013). Multifractal Detrended Cross-Correlation Analysis Between the Chinese Stock Market and Surrounding Stock Markets. Physica A, 392(7):1659-1670.

Mandelbrot, B. (1963). New Methods in Statistical Economics. Journal of Political Economy, 71(5):421-440.

Mantegna, R. N. (1999). Hierarchical Structure in Financial Markets. The European Physical Journal B-Condensed Matter and Complex Systems, 11(1):193-197.

Mantegna, R. N. and Stanley, H. (1999). Introduction to Econophysics: Correlations and Complexity in Finance. Cambridge University Press, Cambridge, UK.

Martin-Montoya, L., Aranda-Camacho, N., and Quimbay, C. (2015). Long-Range Correlations and Trends in Colombian Seismic Time Series. Physica A, 421:361-370.

Matesanz, D., Torgler, B., Dabat, G., and Ortega, G. J. (2014). Co-movements in Commodity Prices: A Note Based on Network Analysis. Agricultural Economics, 45(S1):1321.

Minoiu, C., Kang, C., Subrahmanian, V. S., and Berea, A. (2015). Does Financial Connectedness Predict Crises? Quantitative Finance, 15(4):607-624. 
Minoiu, C. and Reyes, J. A. (2013). A Network Analysis of Global Banking: 1978-2010. Journal of Financial Stability, 9(2):168-184.

Newman, M. (2018). Networks. Oxford University Press.

Obstfeld, M. (1994). Risk-Taking, Global Diversification, and Growth. The American Economic Review, 84(5):1310-1329.

Onnela, J. P., Chakraborti, A., Kaski, K., Kertesz, J., and Kanto, A. (2003). Dynamics of Market Correlations: Taxonomy and Portfolio Analysis. Physical Review E, 68(5):056110.

Peng, C., Buldyrev, S., Havlin, S., Simons, M., Stanley, H., and Goldberger, A. (1994). Mosaic Organization of DNA Nucleotides. Physical Review E, 49:1685-1689.

Pereira, E., Ferreira, P., da Silva, M., Miranda, J., and Pereira, H. (2019). Multiscale Network for 20 Stock Markets Using DCCA. Physica A, 529:121542.

Peters, E. (1991). Chaos and Order in the Capital Markets: A New View of Cycles, Prices, and Market Volatility. John Wiley \& Sons, New York.

Peters, E. (1994). Fractal Market Analysis: Applying Chaos Theory to Investment and Economics. John Wiley \& Sons, New York.

Piao, L. and Fu, Z. (2016). Quantifying Distinct Associations on Different Temporal Scales: Comparison of DCCA and Pearson Methods. Scientific Reports, 6:36759.

Podobnik, B., Jiang, Z., Zhou, W., and Stanley, H. (2011). Statistical Tests for Powerlaw Cross-Correlated Processes. Physical Review E, 84:1-8.

Podobnik, B. and Stanley, H. (2008). Detrended Cross-Correlation Analysis: A New Method for Analyzing Two Non-stationary Time Series. Physical Review Letters, 100(8):084102.

Rachev, S., Weron, A., and Weron, R. (1999). CED Model for Asset Returns and Fractal Market Hypothesis. Mathematical and Computer Modelling, 29:23-36.

Rua, A. and Nunes, L. C. (2009). International Comovement of Stock Market Returns: A Wavelet Analysis. Journal of Empirical Finance, 16(4):632-639.

Schweitzer, F., Fagiolo, G., Sornette, D., Vega-Redondo, F., Vespignani, A., and White, D. R. (2009). Economic Networks: The New Challenges. Science, 325(5939):422-425.

Serletis, A. and King, M. (1997). Common Stochastic Trends and Convergence of European Union Stock Markets. The Manchester School, 65(1):44-57. 
Shi, W., Wang, S., and Lin, A. (2014). Multiscale Multifractal Detrended CrossCorrelation Analysis of Financial Time Series. Physica A, 403:35-44.

Soramäki, K., Bech, M. L., Arnold, J., Glass, R. J., and Beyeler, W. E. (2007). The Topology of Interbank Payment Flows. Physica A, 379(1):317-333.

Sornette, D. (2003). Why Stock Markets Crash? Critical Events in Complex Financial Systems. Princeton University Press, Princeton, NJ.

Stanley, H., Afanasyev, V., Amaral, L., Buldyrev, S., Goldberger, A., Havlin, S., Leschorn, H., Maass, P., Mantegna, R., Peng, C., Prince, P., Salinger, M., Stanley, M., and Viswanathan, G. (1996). Anomalous Fluctuations in the Dynamics of Complex Systems: From DNA and Physiology to Econophysics. Physica A, 224(1):302-321.

Tabak, B. M., Takami, M., Rocha, J. M., Cajueiro, D. O., and Souza, S. R. (2014). Directed Clustering Coefficient as a Measure of Systemic Risk in Complex Banking Networks. Physica A, 394:211-216.

Tilfani, O., Ferreira, P., and El Boukfaoui, M. Y. (2019). Dynamic Cross-Correlation and Dynamic Contagion of Stock Markets: A Sliding Windows Approach with the DCCA Correlation Coefficient. Empirical Economics.

Tumminello, M., Aste, T., Di Matteo, T., and Mantegna, R. N. (2005). A Tool for Filtering Information in Complex Systems. Proceedings of the National Academy of Sciences, 102(30):10421-10426.

Usman, A., Syed, Z., and Qiasar, A. (2015). Robust Analysis for Downside Risk in Portfolio Management for a Volatile Stock Market. Economic Modelling, 44:86-96.

Valls, C. (2012). Rational Integrability of a Nonlinear Finance System. Chaos Soliton \& Fractals, 45:141-146.

Wang, G., Xie, C., Han, F., and Sun, B. (2012). Similarity Measure and Topology Evolution of Foreign Exchange Markets Using Dynamic Time Warping Method: Evidence From Minimal Spanning Tree. Physica A, 391:4136-4146.

Wang, G. J., Xie, C., Chen, S., Yang, J. J., and Yang, M. Y. (2013a). Random Matrix Theory Analysis of Cross-Correlations in the US Stock Market: Evidence From Pearson's Correlation Coefficient and Detrended Cross-Correlation Coefficient. Physica A, 392(17):3715-3730.

Wang, G. J., Xie, C., Chen, Y. J., and Chen, S. (2013b). Statistical Properties of the Foreign Exchange Network at Different Time Scales: Evidence From Detrended CrossCorrelation Coefficient and Minimum Spanning Tree. Entropy, 15(5):1643-1662. 
Wang, G. J., Xie, C., He, K., and Stanley, H. E. (2017). Extreme Risk Spillover Network: Application to Financial Institutions. Quantitative Finance, 17(9):1417-1433.

Watts, D. J. and Strogatz, S. H. (1998). Collective Dynamics of 'Small-World' Networks. Nature, 393(6684):440-442.

Yan, X. G., Xie, C., and Wang, G. J. (2014). The Stability of Financial Market Networks. EPL (Europhysics Letters), 107(4):48002.

Yellen, J. (2013). Interconnectedness and Systemic Risk: Lessons From the Financial Crisis and Policy Implications. Board of Governors of the Federal Reserve System, Washington, DC.

Zebende, G. (2011). DCCA Cross-Correlation Coefficient: Quantifying a Level of CrossCorrelation. Physica A, 390(4):1643-1662.

Zhao, X., Shang, P., and Huang, J. (2017). Several Fundamental Properties of DCCA Cross-Correlation Coefficient. Fractals, 25(2):1750017. 